\title{
Ética y formación de investigadores: la importancia de las virtudes y la sabiduría práctica
}

Ethics and Researchers Training: The Importantes of Virtue and Practical Wisdom

Ética e formação de pesquisadores: a importância das virtudes e a sabedoria prática

Raúl Cuadros-Contreras* iD orcid.org/0000-0003-1357-0021

Para citar este artículo: Cuadros-Contreras, R. (2019). Ética y formación de investigadores: la importancia de las virtudes y la sabiduría práctica.. Revista Colombiana de Educación, 1(79). 223-242. hetps://doi.org/10.17227/rce.num79-7972.

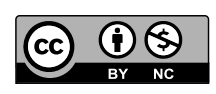

Recibido: 12/05/2018

Evaluado: 18/06/2018

* Doctor en Historia y Teoría de las Artes. Profesor asistente de la Universidad Pedagógica Nacional, Bogotá, 


\section{Resumen}

En el artículo se defiende la importancia de los modelos o enfoques de pensamiento ético como marcos indispensables para ampliar el horizonte de sentido de la ética aplicada, más si se trata de promover la formación ética de investigadores. Se exponen brevemente los dos enfoques predominantes del pensamiento ético en nuestro tiempo (consecuencialismo y deontologismo), y se señalan algunas de sus limitaciones. Posteriormente se reivindica un enfoque antiguo pero cada vez más vigente: el enfoque de las virtudes, que más que centrarse en principios o en el cálculo de las consecuencias, concede primacía al ejercicio de la sabiduría práctica anclado en la formación del carácter. Al final se insiste en la bondad de un enfoque como este, que nos separa de una visión meramente defensiva de la ética de la investigación, a la que se opone una concepción afirmativa, que vincula las decisiones éticas con la busca de la realización personal del investigador y de los sujetos y comunidades con los que investiga.

\section{Palabras clave}

ética; formación investigadores; enfoque; moral

\section{Keywords}

ethics; training; researchers; approach; morale

\begin{abstract}
The article defends the importance of the models or approaches of ethical thought as indispensable frameworks to broaden the horizon of meaning of applied ethics, even more so if it is a matter of promoting the ethical training of researchers. The two predominant approaches to ethical thinking in our time, consequentialism and deontologism, are briefly exposed and some of their limitations are pointed out Later, an old but increasingly valid approach is claimed-the focus of the virtueswhich rather than focusing on principles or calculating the consequences, gives primacy to the exercise of practical wisdom anchored in the formation of character Finally, the authors insist on the convenience of such an, which separates us from a merely defensive vision of the ethics of research, which is opposed by an affirmative conception, which links ethical decisions with the search for the personal

realization of the researcher, the subjects and communities he researches with.
\end{abstract}

\section{Resumo}

O artigo defende a importância dos modelos ou abordagens do pensamento ético como marcos indispensáveis para ampliar o horizonte de significado da ética aplicada, especialmente se for para promover a formação ética dos pesquisadores Apresentamos brevemente as duas abordagens predominantes para o pensamento ético em nosso tempo (consequencialismo e deontologismo) e assinalamos algumas de suas limitações. Depois reivindicamos uma abordagem antiga, mas cada vez mais válida: a abordagem das virtudes, que, em vez de enfocar princípios ou calcular as consequências, dá primazia ao exercício da sabedoria prática ancorada na formação do caráter. No final, insistimos nas vantagens de uma abordagem como esta, que nos separa de uma visão puramente defensiva da ética da pesquisa, à qual se opõe uma concepção afirmativa que liga as decisões éticas com a busca da realização pessoal do pesquisador e dos sujeitos e comunidades alvo de sua pesquisa.

\section{Palavras-chave}

ética; formação; pesquisadores; abordagem moral 


\section{Una cuestión preliminar: la importancia de los enfoques}

Muchos piensan o actúan como si, en el momento de tratar algún asunto de ética aplicada, no fuera preciso considerar las distintas tradiciones de pensamiento ético, como si no hubiera necesidad de apelar a modelos de razonamiento ético. Por nuestra parte, en cambio, partimos de conceder toda la importancia a dichas tradiciones o modelos de pensamiento.

El caso de la ética de la investigación no representa una excepción a esta norma. Más aún, consideramos preciso sostener que, a la creciente inquietud sobre este tema y a muchos de los importantes trabajos empíricos emprendidos en este vasto y heterogéneo campo, les vendría muy bien someterse al escrutinio teórico de dichas tradiciones o modelos de pensamiento ético. Muchos se preguntarán por qué, pues, ¿acaso la ética no es un asunto que compete a todos los seres humanos? En principio estamos de acuerdo con esta aseveración, precedida de un antecedente clásico invaluable ${ }^{1}$.

No obstante nuestra larga experiencia en la enseñanza de la ética, tanto a profesionales en el campo de la filosofía como a profesionales de muchas otras disciplinas, nos han persuadido de que es preciso considerar que, al menos en la cultura occidental, dichas tradiciones o modelos parecen imponerse sin saberlo cuando deliberamos sobre asuntos morales, es decir que, aun sin que lo sepamos, solemos discurrir cual utilitaristas, o cual kantianos o deontologistas, o cual aristotélicos.

Por otra parte, el estudio de dichas tradiciones nos permite apelar a un rico universo de posibilidades conceptuales, que nos pertrecha de opciones analíticas invaluables. Ahora bien, si dichos modelos o tradiciones han servido para pensar los problemas de la vida ética personal y pública de cientos de generaciones, pues, en cuanto tradiciones, se trata de formas de pensar vivas que persisten y se reformulan enfrentando las vicisitudes de las nuevas épocas; no tenemos razones para no creer que albergan en su seno posibilidades analíticas valiosas para nuestros asuntos particulares en el campo de la ética de la investigación. Si alguien creyera lo contrario estaría invocando una excepcionalidad extrema para nuestro campo. En ese caso sería preciso hacer dos exigencias: la primera, que se demuestre por qué la ética de la investigación representa semejante excepcionalidad con respecto al resto de la vida ética pública y privada; la segunda, que

1 Es conocido que en el célebre diálogo platónico El Protágoras, este cuenta un mito para mostrar cómo Zeus repartió por igual la virtud política a todos los hombres, a diferencia de otras virtudes ligadas a la técnica o al conocimiento: "Que cada uno tenga su parte en estas virtudes: ya que si solamente las tuvieran algunos, las ciudades no podrían subsistir, pues aquí no ocurre como en las demás artes" (Protágoras, 322b. Trad. M. Araújo et al., Editorial Aguilar, 1981). 
es preciso encontrar puentes o vínculos entre la vida profesional y la vida personal, para que haya cierta coherencia o consistencia ética en nuestra vida como sujetos y ciudadanos. De alli que, si consideramos valiosos estos modelos para nuestras vidas, no hay razón para no concederles la misma valoración en la esfera profesional de la ética de la investigación.

Dicho esto, hemos de presentar de manera breve las dos tradiciones más fuertes de pensamiento ético, consecuencialismo y deontologismo, para lo cual seguiremos muy de cerca —si bien introduciendo algunos matices - el texto de María Amalia Amaya Navarro Virtudes judiciales y argumentación: una aproximación a la ética jurídica (2009), para después defender la prioridad de una tradición muy antigua, pero que emerge de nuevo con gran fortaleza y que puede resultar fundamental para la empresa de la formación ética de nuestros investigadores, la tradición de las virtudes.

\section{Consecuencialismo}

En esta tradición, la corrección moral depende de las consecuencias que se derivan de una acción, por tanto, se puede evaluar una acción como moralmente correcta en la medida que las cosas que produzca sean buenas. Dentro de esta teoría, correcto equivale a bueno, y una acción correcta será aquella que maximice lo bueno.

Todas las teorías consecuencialistas contemporáneas son descendientes del utilitarismo de Jeremy Bentham (1789) y John Stuart Mill (1861). Según el utilitarismo clásico, un acto es moralmente correcto, si y solo si, produce la mayor felicidad para el mayor número de gente posible. Por lo tanto, el utilitarismo clásico identifica lo bueno con la felicidad y considera que las consecuencias relevantes para determinar la corrección moral de un determinado acto son las consecuencias actuales del mismo (Amaya, 2009, p. 14).

Dependiendo de lo que se entienda por bueno, la teoría consecuencialista podrá tener varias versiones, por ejemplo, posiciones consecuencialistas contemporáneas consideran que el bien puede ser la satisfacción de los deseos, el bienestar, etc. En todo caso, conviene aclarar, en oposición a las simplificaciones y tergiversaciones en contra de esta perspectiva que, a partir de Mill — si bien ya hay un avance en esta dirección en Bentham - la consideración de los placeres implica el reconocimiento de una cierta noción de dignidad humana:

Lo más adecuado es apelar a un grado de dignidad que los seres humanos poseen en un grado u otro y que guarda alguna correlación, aunque en modo alguno perfecta, con sus facultades más elevadas y que constituye una parte tan esencial de la felicidad de aquellos 
en los que este sentimiento es fuerte, que nada que se le oponga podría constituir más que un objeto momentáneo de deseo para ellos. Quien quiera que suponga que esta preferencia tiene lugar al precio de sacrificar la felicidad confunde los conceptos totalmente distintos de felicidad y contento. (Mill, 1984, pp. 50-51).

Algunas teorías consecuencialistas contemporáneas también se apartan del utilitarismo clásico, en cuanto niegan que las consecuencias relevantes para determinar la corrección moral de un acto sean las consecuencias actuales del mismo. Según estas teorías, los agentes morales deben actuar con base en las reglas que tienen las mejores consecuencias: "Un acto es obligatorio solo si la aceptación uniforme de una regla correspondiente maximizara la utilidad esperable" (Brandt, 2006, p. 464), en lugar de tratar de maximizar las mejores consecuencias del acto concreto. Algunas versiones consecuencialistas sostienen así lo que se ha llamado un "utilitarismo de reglas" en vez de un "utilitarismo de actos" (Amaya, 2009, p. 14), pues:

La nueva versión del utilitarismo modifica la teoría, de modo que las acciones particulares ya no van a ser juzgadas por el principio de utilidad. En cambio, primero preguntamos qué conjunto de reglas es óptimo desde un punto de vista utilitarista. ¿Qué reglas debemos preferir como vigentes en nuestra sociedad, para que prospere la gente en ella? Los actos particulares se juzgan entonces como correctos o incorrectos según si son aceptados o no por esas reglas. (Rachels, 2006, p. 183. Énfasis del original).

\section{Deontologismo}

En esta corriente la acción moralmente correcta no será aquella que tenga las mejores consecuencias, sino aquella que se haga con base en una norma moral. Para los deontologistas, lo correcto tiene primacía sobre lo bueno y no al contrario.

Si un acto no es correcto, en el sentido de que no es un acto conforme a las normas de la moral, entonces ese acto no está permitido, independientemente de las buenas consecuencias que este pueda tener (Amaya, 2009, p. 15).

Al igual que el consecuencialismo, dentro de la deontología también existen diferentes tipos, sin embargo, todas parten de lo planteado por Kant y consideran los deberes impuestos por las normas morales como básicos para la evaluación moral de la conducta. En Kant, la noción del deber es clave, como aquello que se hace únicamente por respeto a la ley moral y sin que entre ninguna otra consideración de interés, satisfacción o conveniencia, incluso ninguna otra relativa a los afectos nobles hacia los demás. 
Las concepciones deontologistas posteriores han limado este rigorismo racionalista que niega toda posibilidad a las inclinaciones o emociones como fuente del bien moral. Mantienen la importancia de las normas o principios, pero estos también han sido objeto de reflexión y sofisticación, pues, en su versión original el deontologismo está fundado en una noción fuerte de sujeto desvinculado de lo social y porque en nuestro tiempo resulta clave encontrar otras fuentes de justificación de la normatividad moral.

Para estudiosos contemporáneos como Allen W. Wood (2007), no se trata de que Kant recomiende que cada decisión que se toma en la vida deba hacerse preguntándose si puede traducirse a una máxima² deseable como ley universal: la fórmula de ley universal solamente provee un test o límite negativo para las máximas (rechazar algo como impermisible), sin decir en términos positivos qué o cómo debe seguirse una máxima específica. La función del principio de moralidad no es dictar qué hacer en cada caso concreto, sino más bien justificar un sistema general de reglas o deberes morales y proveer una racionalidad general para decidir casos de los que derivan razones que colisionan y en los que resulta difícil decidir qué hacer.

Para Habermas (2000), de lo que se trata es de fundamentar los imperativos morales, ya no desde una racionalidad individual supuesta en toda la humanidad y basada en conceptos a priori, sino en el ejercicio intersubjetivo del diálogo. Esto supone una cierta inversión del imperativo categórico kantiano, el cual fue postulado por Kant como un deber por sí mismo, asumiendo como dado el principio de justificación, es decir, de la validez del deber. La inversión reside en que no es la persona la que considera que su acción puede llegar a convertirse en ley universal, sino, por el contrario, debe someter su acción y argumentación a la libre deliberación de todos para probar su validez (verdad para las personas implicadas en el diálogo) y con ello acercarse a la pretensión de universalidad. Lo que Habermas sostiene es que "aquello que esté justificado en sentido moral tienen que poder quererlo todos los seres racionales" (Habermas, 2000, p. 15).

Por su parte, para Christine Korsgaard, la respuesta a la pregunta normativa es que la reflexión es la fuente de la normatividad. Formulándolo de manera más precisa: la autonomía es la fuente de la obligación. El ser humano tiene naturaleza moral en virtud de su capacidad de darse normas a través de la autorreflexión. Para esta autora, las leyes de la moralidad son las leyes dadas por la voluntad del agente y sus exigencias son las que el

2 Con máxima Kant se refiere a un principio normativo que un sujeto establece para sí mismo con la intención de actuar conforme a él. Presupone que entender una acción implica entender la intención del agente. 
agente está dispuesto a hacerse. Como agentes, estamos obligados a hacer lo que debemos hacer, y como agentes nos preguntamos por qué motivo debemos hacerlo. De acuerdo con Korsgaard:

[l]a ética de la autonomía es la única compatible con la metafísica del mundo moderno, y la ética de la autonomía es una ética de la obligación

Nietzsche tenía razón cuando les advirtió a los enemigos de la obligación que se guardaran de tenerla en poco por el hecho de ser fea y dolorosa, pues la obligación es lo que nos hace humano. (2000, p. 17)

De acuerdo con esta perspectiva, es la reflexión la que nos constituye como agentes, es decir, en la causa de lo que hacemos, en fuente del asentimiento hacia lo que consideramos correcto y pertinente hacer en cada momento. En todo caso, prevalece ese sentido fuerte de imparcialidad, de no basar nuestras decisiones morales en nuestros meros intereses o conveniencias particulares, detrás de lo cual palpita también ese sentido fuerte de la dignidad humana que aparece en las distintas formulaciones de los "imperativos categóricos" que son las formas que adquiere la ley moral que nos damos a nosotros msmos como sujetos libres:

1. Fórmula de la ley universal: "Obra solo según aquella máxima por la cual puedas querer que al mismo tiempo se convierta en una ley universal" (Fundamentación, Ak. 4, p. 421; cf. 4, p. 402) 3. $^{3}$

2. Fórmula del fin en sí mismo: "Obra de tal modo que tomes en cuenta a la humanidad, tanto en tu persona con en la persona de cualquier otro, siempre al mismo tiempo como fin y nunca simplemente como medio" (Fundamentación, Ak. 4:429; cf. 4, p. 436).

Existen casos problemáticos que ponen en cuestión estas maneras de interpretar las acciones en sentido moral. Muchas veces resulta difícil ser consecuencialista, en cuanto es casi imposible saber con precisión todas las consecuencias que podrían derivar de una decisión. Otra objeción común a este enfoque es que, en busca de las buenas consecuencias se puede validar una acción que no sea correcta, en cuanto resulta válido sacrificar a alguien o a una minoría por estar en busca del bien para la mayoría.

El paradigma deontologista también resulta cuestionado cuando se trata de enfrentar casos difíciles, en los que hay conflictos entre deberes o derechos. En casos de conflicto entre normas morales, el deontologista tiene dificultad para ofrecer una guía o un procedimiento de decisión

3 A continuación se agrega la nomenclatura atendiendo a la edición canónica de referencia de la obra de Kant, la Akademie-Ausgabe (Ak). 
adecuado. Por otra parte, según el deontologista, la corrección moral depende del cumplimiento de normas, pero, a veces, tal cumplimiento puede tener consecuencias trágicas (Amaya, 2009).

Entre otros problemas, el punto débil del deontologismo continúa siendo su tendencia a concebir las normas morales como normas absolutas y a minimizar el papel que juegan las consecuencias en la valoración de la acción, incluso en casos donde las mismas son trágicas. Además, el deontologismo clásico — Kant- no toma en cuenta para nada la historia concreta de los sujetos, solo considera la acción y la norma, pero por fuera de todo marco histórico o cultural. El punto débil del consecuencialismo es que, en principio, permite —más bien, requiere-que se maximicen las mejores consecuencias, aunque esto suponga la violación de derechos básicos (Amaya, 2009).

Con todo, es preciso insistir en que, por muchos que sean los cuestionamientos a estos enfoques o modelos de razonamiento ético, lo cierto es que en la vida diaria tendemos a apelar a alguno de ellos para caracterizar todo tipo de situaciones y conflictos morales, y a justificar nuestras decisiones sobre ellos usando alguno de estos dos modelos. Por lo demás, en nuestra sociedad, cuando hay conciencia de la necesidad de un enfoque ético para orientar la acción, predomina la apelación al enfoque deontológico, si bien, en la mayoría de las veces, desde una comprensión muy restringida, esto debido a la fuerte tradición formalista de la idiosincracia colombiana.

\section{El problema de la caracterización de la acción moral y sus límites}

Una cuestión clave en este debate sobre los enfoques o modelos es la de la caracterización de la acción moral y sus límites. Si hay algo que separa la tradición aristotélica y las dos tradiciones predominantes que venimos discutiendo es la consideración de la acción moral y sus límites. Pues una cosa es considerar la acción moral como algo restringido al presente inmediato de los agentes morales y otra muy distinta, relacionarla con la vida misma de dichos agentes. A propósito, en un trabajo reciente hemos abordado este asunto a partir del análisis de ciertos pasajes poco discutidos de la obra de Aristóteles:

Uno podría preguntarse cómo decimos que los hombres han de hacerse justos practicando la justicia, y moderados, practicando la moderación, puesto que si practican la justicia y la moderación son ya justos y moderados, del mismo modo que si practican la gramática y la música son gramaticales y músicos. Pero ni siquiera este es el caso de las artes. Pues es posible hacer algo gramatical, o por casualidad o por sugerencia 
de otro. Así pues, uno será gramático si hace algo gramatical o gramaticalmente, es decir, de acuerdo con los conocimientos gramaticales que posee. Además, no son semejantes el caso de las artes y el de las virtudes, pues las cosas producidas por las artes tienen su bien en sí mismas; basta, en efecto, que, una vez realizadas, tengan ciertas condiciones; en cambio, las acciones, de acuerdo con las virtudes, no están hechas justa o sobriamente si ellas mismas son de cierta manera, sino si también el que las hace está en cierta disposición al hacerlas, es decir, en primer lugar, si sabe lo que hace; luego, si las elige, y las elige por ellas mismas; $y$, en tercer lugar, si las hace con firmeza e inquebrantablemente. Estas condiciones no cuentan para la posesión de las demás artes, excepto el conocimiento mismo; en cambio, para la de las virtudes el conocimiento tiene poco o ningún peso, mientras que las demás condiciones no lo tienen pequeño sino total, ya que surgen, precisamente, de realizar muchas veces actos justos y moderados. (Ética Nicomáquea, 1105a 20, 25, 30-1105b. Trad. J. P. Bonet, Editorial Gredos, 2010).

En esta cita aparece toda una concepción de la acción moral en la que salta a la vista el contraste con los dos enfoques que venimos estudiando. Para Aristóteles, la acción moral, para ser tal, precisa de la consideración de múltiples determinaciones que hacen que sea imposible circunscribirla al horizonte limitado de las circunstancias presentes. En ella, la acción moral se prolonga más allá de estas y aparece anclada al carácter. Se advierte así una relación de determinación entre el agente y la acción "sin tomar en cuenta las disposiciones del que las realiza":

Estas son, así tal cual son dichas de manera condensada: si el que las hace sabe lo que hace — no por casualidad o inadvertidamente-, si las elige, esto es si ha habido un proceso de deliberación previa, lo que implica que lo decidió y no le fue impuesto hacerlas o no las hace en contra de su voluntad, y si las elige por ellas mismas, lo que implica que al decidir las considera un fin en sí, un bien, y no un medio para conseguir otras cosas (idea que tiene un sabor kantiano inconfundible y que se repite en otros pasajes). Pero también está el asunto de que debe hacerlas con firmeza e inquebrantablemente, lo que implica que debe ser algo coherente con su modo de ser, de modo que tenga convicciones fuertes en el momento de decidir y que quien las haga se encuentre comprometido al hacerlas. Así vista, la teoría de la acción moral de Aristóteles es bastante exigente y sintetiza en buena medida su concepción de la moral. Una aproximación como esta problematiza también lo que está en juego en el esfuerzo de comprender los problemas morales, en especial las acciones y las decisiones. (Cuadros, 2016, pp. 23-25).

Es esta relación de determinación entre el agente y la acción la que aparece en primer plano en un enfoque como el de las virtudes, que es el que aquí reivindicamos como clave para la formación de investigadores. 
Pues, por más importancia que pueda concederse al establecimiento de principios o incluso protocolos de ética de la investigación —-tarea a la que sin duda es preciso dedicar esfuerzos institucionales- (visión deontológica que predomina en el ámbito de la ética de la investigación, de manera casi ingenua), no podemos eludir la complejidad de la acción moral restringiendo nuestras pretensiones a que los investigadores - como agentes morales - se ciñan a tales o cuales principios o lineamientos sin antes preocuparnos por ver si ellos reconocen la centralidad de los asuntos morales en sus trabajos cotidianos de investigación y, más aún, si consideran que existen implicaciones entre su práctica investigativa y su vida personal y ciudadana que reclame cierta coherencia ética.

Por otra parte, tampoco se trata, única o principalmente, de que consideren meticulosamente las consecuencias de sus acciones, o de que consideren todos los riesgos posibles (versión contemporánea del consecuencialismo). Pues, la delimitación misma de las acciones es ya algo complejo, a lo que se suma el hecho de que predecir consecuencias suele resultar en extremo complicado, por la multiplicidad de variables que pueden implicarse en cada caso y la dificultad de advertirlas. Pero también porque los asuntos éticos parecen estar destinados a implicarnos de modos tan cruciales para nuestras vidas que no pueden ser evaluados desde perspectivas tan estrechas como las de las reglas del deber o el cálculo de las consecuencias posibles. Es en este marco que acogemos el modelo de las virtudes, tal como lo recuerda Maclntyre:

Pero el ejercicio de las virtudes no es un medio en este sentido para el fin del bien del hombre. Lo que constituye el bien del hombre es la vida humana completa vivida al óptimo, y el ejercicio de las virtudes es parte necesaria y central de tal vida, no un mero ejercicio preparatorio para asegurársela. No podemos caracterizar adecuadamente el bien del hombre sin haber hecho ya referencia a las virtudes. Y dentro del sistema aristotélico la sugerencia además de que podrían existir algunos medios de lograr el fin del hombre sin el ejercicio de las virtudes, carece de sentido. (Maclntyre, 2001, p. 188).

\section{De cómo deontologismo y consecuencialismo coinciden en una formulación defensiva de la ética de la investigación}

La ética no es un asunto de códigos o de reglamentos, si bien no excluye la posibilidad o hasta la necesidad de dichos recursos. Una primera y primordial inclinación llama a resistirse a entender la ética como una práctica dócil, emparentada con el ejercicio de reglamentación de nuestras acciones o de nuestros deseos. Otra, que se encuentra muy cercana a la primera, 
conduce a oponerse a presentar la ética como una mera salvaguarda — por muy bien intencionada que sea-contra nuestras tendencias destructivas, como algo que tendría que ver esencialmente con la prevención del riesgo; más aún, con la tarea de proporcionar herramientas o fórmulas que pudieran ponernos a salvo del peligro de errar o de hacer daño.

No desconocemos que existen buenas razones para creer que la ética deba ocuparse esencialmente de este tipo de salvaguardas: la experiencia atroz del siglo xx, como bien ha mostrado Jonathan Glover (2001), que, por lo demás, motivó la emergencia de preocupaciones y prácticas éticas en múltiples ámbitos de la vida, ha llevado a pensar así. Incluso, es menester reconocer la importancia de la impronta instaurada por el Ilamado principio de precacución, tal como aparece formulado en la declaración de Wingspread: "Cuando una actividad hace surgir amenazas de daño para el medio ambiente o la salud humana, se deben tomar medidas de precaución incluso si no se han establecido de manera científica plena algunas relaciones de causa-efecto" (Wingspread-Wisconsin, 1998).

Pero, es preciso no perder de vista que una concepción meramente defensiva de la ética, como esa que emergió en dichos contextos, olvida la existencia de tradiciones éticas antiguas y robustas que no se limitan a la prevención, sino que tienen, al contrario, un sentido afirmativo fuerte. Menos todavía que, según dichas tradiciones, la ética no puede quedar reducida a una especie de técnica o gestión del cuidado o de la prevención, por más valiosa y necesaria que esta pueda resultar (como por lo demás ha quedado demostrado con la irrenunciabilidad de la bioética en múltiples ámbitos de la vida científica, técnica y profesional contemporánea), pues, según estas tradiciones, la ética tendría que ver sobre todo con la búsqueda de la felicidad.

Se puede pensar que se exagera, y en efecto hay algo de eso, para acentuar una diferencia, pero, lo cierto es que dicha manera de presentar la ética de la investigación se corresponde con la actitud predominante en nuestro medio académico, aquella de no ser capaces de concebir un ámbito del conocimiento que no escape a la instrumentalización, a la mera facticidad, a la certeza y, en última instancia, a la sensación de seguridad. Aun cuando, en realidad, no existe ninguna comarca del conocimiento en la que podamos conducirnos completamente con acierto, contando con caminos despejados y completamente seguros, ni con guías bien instruidos, confiables y sensatos, y menos aún con metas claras y bien determinadas de antemano.

Contra esa tendencia es necesario manifestarse abiertamente, mucho más cuando se trata de pensar las relaciones entre conocimiento o busca del conocimiento y ética, pues no es posible dar ningún paso en procura de la formación de investigadores desde una perspectiva moral, sino se abandona esa representación tranquilizadora acerca de lo que es la ética.

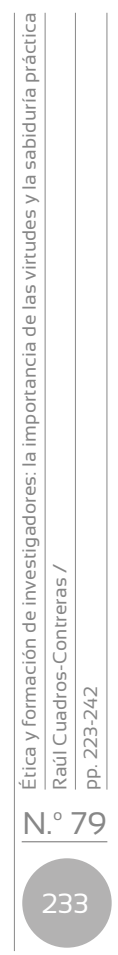




\section{La ética como saber práctico, una perspectiva neoaristotélica}

Partimos del hecho de que la ética no es un saber teórico, sino un antiguo saber sobre nosotros mismos cuyo centro es el perfeccionamiento del obrar. En ese sentido, es un saber práctico. Como su finalidad no es el conocimiento, sino la búsqueda del bien, lo que implica la correcta examinación de la vida humana, esto repercute en las posibilidades y las exigencias de su enseñanza. Como la ética no consiste en postular principios o leyes inmutables que determinen el modo de ser de los hombres, no es algo que pueda enseñarse dogmáticamente. De allí que, más que de promover una enseñanza o formación en valores, de lo que se trata es de enseñar a discernir sobre valores con el propósito de ayudar a que se aprenda a justificar razonablemente las distintas opciones valorativas, y esto con más urgencia en sociedades tan heterogéneas como las actuales.

Ahora bien, la ética tampoco es un saber metafísico, y aquí encontramos la crítica aristotélica hecha a Platón, pues el bien no aparece en el mundo social como una idea; por el contrario, el bien adquiere formas variadas y concretas. El hombre no busca la idea trascendente del bien, sino la que resulta precisa para cada caso. De allí la primacía del caso que se corresponde con esa situacionalidad inherente a lo humano a la que aludimos más arriba.

En este marco convendría apelar a una noción de ética centrada en la promoción de virtudes más que en la disposición de reglas o principios, por muy útiles que estos puedan ser en muchos casos. Ya Aristóteles distinguió entre saberes teóricos, poiéticos y prácticos. Mientras en los primeros la razón se ocupa del conocimiento del mundo, esto es, de averiguar y describir qué son las cosas (verbigracia el caso de la física, la química, la biología, etc.), los últimos — poiéticos y prácticos — versan sobre "lo que puede ser de otra manera", dimensiones de la vida en las que el problema de la voluntad y la decisión están en primer plano.

Mientras que los saberes poiéticos sirven de guía para la elaboración de productos u obras (entre estos se cuentan las distintas técnicas y las artes), en los saberes prácticos la razón se dirige a orientar la acción, o sea, sirve de guía para conducir la vida. Más allá de los problemas de conocimiento sobre el mundo, de lo que se trata en estos ámbitos es de saber cómo actuar. Es ese el lugar de la ética que reclama un uso particular de la racionalidad: la racionalidad que se ejerce predominantemente en la vida cotidiana cada vez que se toman decisiones y se actúa. Pues la ética tiene que ver con la búsqueda efectiva del bien en el mundo concreto, en cada decisión y en cada acción importante pública o privada. Pero esto no es precisamente un asunto intelectual, de 
conocimiento, sino un problema práctico, que involucra tanto a nuestras disposiciones éticas asentadas en el carácter como al uso de la razón dirigida al obrar (Gadamer, 1991).

A diferencia de la perspectiva de la racionalidad práctica kantiana, en la que son los principios formales y racionales los que pueden guiar sustancialmente las elecciones y conductas, desde una perspectiva aristotélica, no son los principios, sino las virtudes las que constituyen los elementos fundamentales de una teoría del razonamiento práctico (Amaya, 2012). Precisamente, en cuanto virtud, la sabiduría práctica tiene una naturaleza distinta a la del conocimiento científico y no puede limitarse al dominio de un cuerpo sistemático de principios generales o universales. Por el contrario, la sabiduría práctica se relaciona con los particulares y las situaciones concretas: "Es evidente que el médico no considera así la salud (que es por supuesto un bien), sino la salud del hombre, o, más bien aún, la de este hombre, ya que cura a cada individuo" (EN, 1097a10).

\section{La importancia de la formación}

Nada de esto es posible sin un sentido fuerte de formación, sin la producción de un sentido común afectivo y valorativo que acompañe, desde los primeros momentos en la temprana edad, hasta los más grandes hitos de nuestra carrera académica, el esfuerzo por conocer. Porque ese sentido común compartido, ese sentido fuerte de nosotros (que incluye no solo lo idéntico o lo más cercano, sino, con frecuencia, a otros muy distintos, incluso a los no humanos) es el que nos permite anteponer las preguntas éticas: aquellas referidas tanto a los fines como a los medios de la investigación, las que se ocupan de las consecuencias de las acciones y, sobre todo, las que inquieren acerca del sentido de la vida del investigador y los sujetos y comunidades investigadas y sobre los vínculos entre cada acción y dicho sentido de la vida.

Esa idea de formación la encontramos en los griegos desde muy temprano, entre quienes tiene la forma del reconocimiento de la necesidad de crear un tipo ideal íntimamente coherente y claramente determinado. Bajo esta concepción, no es posible la educación sin que se presente al espíritu una imagen del hombre tal como debe ser, una identidad de humanidad (Jaeger, 1992). Esta imagen o ideal no es otra cosa que la belleza, algo grande y sublime donde la utilidad no es importante. Esto por supuesto no es cosa del azar, es producto de la disciplina, es algo consciente, es un producto tanto de la cultura como de la educación. (Cuadros, 2009, p. 18)

Se puede objetar que se trata de una representación demasido cerrada o hasta idealista, tanto de la educación como de los sujetos a ser educados, pero, superando las reservas propias de una actitud posmoderna y

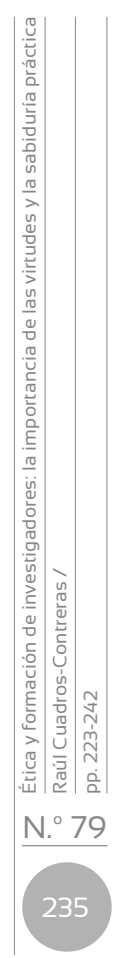


adaptando el lenguaje a las necesidades de nuestro tiempo, es posible y necesario sostener que no tiene sentido hablar de educación sin esa perspectiva fuerte de formación, según la cual es indispensable partir de una imagen de lo que se quiere ser para que las acciones pedagógicas tengan sentido. Esto se hace mucho más evidente cuando se habla de una educación ética, no es posible valorar correctamente el sentido o el alcance de nuestras decisiones y de nuestras acciones morales sin ese anclaje de la imagen de sí, del horizonte de la vida del que hablan los antiguos y sobre el cual teoriza Aristóteles cuando habla de felicidad.

Pero esto supone también que debería poder entenderse el conocimiento no como una aplicación de la teoría a la práctica, sino como un aprendizaje de la práctica misma, pues la praxis y, en primer lugar, la praxis moral no tiene que ver con actuar siguiendo determinadas reglas, sino que está referida a la situacionalidad original del ser humano en su entorno natural y social (Gadamer, 2001).

Las preguntas éticas que incluyen la dimensión de la curiosidad y el cuidado, del respeto, así como del esfuerzo por la realización de vidas plenas, deberían emerger espontáneamente en la vida cotidiana de los estudiantes; deberían acompañar cada acción, cada intento intelectivo, cada operación de diseño, cada prueba empírica. Esto que decimos remite tanto a una problematización del conocimiento como a una problematización de lo que se entiende por ética.

Pero el aprendizaje de estas dimensiones no ocurre en el contexto de los esfuerzos por conocer el mundo natural y su funcionamiento, emerge en el contacto con las experiencias humanas e implica el despliegue de cierto tipo de operaciones (argumentación, narración e interpretación) que solo se aprenden de la mano de las artes y del ejercicio cotidiano de los debates sobre los asuntos candentes de la vida práctica:

\begin{abstract}
Argumentación, interpretación y narración serían las operaciones más características del actuar humano en el mundo social —público y privado- ejercitando una racionalidad particular: la racionalidad práctica, que no se encuentra centrada en el cálculo ni en el despeje de la verdad, sino en el ejercicio de la elección de la deliberación, en la clarificación de las razones que justifican el actuar y en la búsqueda de la comprensión de las acciones humanas. (Cuadros, 2015, p. 14)
\end{abstract}

\title{
La sabiduría práctica: un saber anclado en el carácter
}

La ética tendría que ver, entonces, con una sabiduría práctica anclada en el carácter; así, por más cuestionamientos que puedan hacerse a la noción de carácter (Camps, 2011), lo cierto es que en un mundo tan líquido como el actual pareciera importante volver a preguntarse por la necesidad de 
formar ciertos tipos de caracteres o modos de ser éticos y políticos. Esto resulta aún más válido para la formación científica, pues, sin esa pregunta por el tipo de carácter o modo de ser, la tarea de formar investigadores perdería sentido o quedaría librada a la labor residual de las exigencias técnicas y tecnocráticas de las agencias de financiación. Dicha pregunta por los modos de ser remite a una visión constructiva de la ética y de la investigación científica, en la que formarse como investigador involucra necesariamente examinarse a sí mismo acerca de los objetivos del conocimiento, de la relación de cada uno con la busca del conocimiento y de las implicaciones entre busca del conocimiento y vida social.

Según esto, solo quien entiende su proceso de formación como investigador a la manera del de una empresa, a la vez personal y social, en la que el conocimiento no aparece como un asunto meramente profesional o disciplinar, sino como parte de un esfuerzo comprensivo sobre la vida humana, en general, y sobre la vida de cada comunidad humana, en particular, podrá vivir la experiencia investigativa como un asunto esencialmente humano, en el que las preguntas éticas aparecerán de suyo, como ocurre siempre a aquellos que se preocupan por el bien propio y por el bien de los otros con quienes interactúan. Las preguntas éticas deben aparecer naturalmente a todo investigador comprometido, no deben venirle de algún Olimpo gubernamental, académico o administrativo, si es que la empresa del conocimiento se le aparece como algo más que un encargo laboral extrínseco a su praxis.

La exigencia de sabiduría, como parte central de la formación humana y ciudadana, se nos aparece cada vez más acuciantemente, como bien lo enuncian los representantes del movimiento de la ecología profunda:

[...] el saber científico, si bien muy necesario, es parcializado. Una cosa sería, por ejemplo, preguntar qué es un ecosistema, qué es la simbiosis, cómo funcionan en el medio natural las relaciones entre componentes bióticos y abióticos, y otra muy distinta sería preguntarse cómo y en qué momento, con qué objetivos y hasta qué punto deberíamos ocuparnos científicamente, o de otros modos, de los ecosistemas, de la simbiosis, de las múltiples relaciones ambientales, etc.

En la segunda perspectiva estamos completamente implicados, vamos más allá del saber científico y nos abrimos a una preocupación más integradora, totalizadora que sería la sabiduría. El hombre se interroga acerca de sí mismo; para vivir y actuar desarrolla una sabiduría como fruto de los interrogantes que no puede dejar de plantearse acerca de la totalidad de lo real. (Bugallo, 2011, p. 47)

La sabiduría práctica, o phronesis, actúa en relación con hechos y circunstancias sujetos a la contingencia, pero también con respecto a las dudas e inconsistencias propias de nuestros comportamientos como 
seres humanos falibles. Son muchas las ocasiones en las que no seguimos a nuestra razón. Recuérdese que, para Aristóteles, la phronesis es una virtud racional, pero que posibilita el ejercicio de las virtudes éticas —es decir, de aquellas que tienen que ver con el carácter y la costumbre-. Requerimos de este uso práctico de la razón, no solo por el hecho de que las acciones humanas y las circunstancias que las rodean son cambiantes e inestables, sino también porque, con frecuencia, tendemos a perder el control sobre nuestros actos. Para Aristóteles, a diferencia de los intelectualistas éticos como Platón, existe un hiato entre el conocimiento o el reconocimiento del bien y la acción buena. La sabiduría práctica tiene que ver con esa capacidad humana de sobreponerse a todos estos problemas.

En cuanto a la prudencia, podemos Ilegar a comprender su naturaleza, considerando a qué hombres Ilamamos prudentes. En efecto, parece propio del hombre prudente el ser capaz de deliberar rectamente sobre lo que es bueno y conveniente para sí mismo, no en un sentido parcial, por ejemplo, para la salud, para la fuerza, sino para vivir bien en general. Una señal de ello es el hecho de que, en un dominio particular llamamos prudentes a los que, para alcanzar algún bien, razonan adecuadamente, incluso en materias en las que no hay arte. Así, un hombre que delibera rectamente puede ser prudente en términos generales. Pero nadie delibera sobre lo que no puede ser de otra manera, ni sobre lo que no es capaz de hacer. (EN, 1140a 25)

Por otra parte, la sabiduría práctica es inherente a una perspectiva ética que no se limita a las relaciones medios-fines, sino que contempla sus acciones bajo el horizonte de una vida completa, de la imagen que tengo sobre mí —como sujeto moral—o de la que busco forjarme. Es eso lo que el estagirita comprende bajo el nombre de felicidad o vida buena. Pero, desde esta perspectiva, es muy distinto encarar las decisiones complejas de la vida a reducirlas a la inmediatez de los cálculos de conveniencia o incluso a aquellos en los que se trata de aplicar principios a casos acotados, sin que medie ese horizonte de sentido de la vida, pues, como nos recuerda Ricoeur:

La phronesis se entiende como una capacidad práctica del ser humano, relacionada con el quehacer cotidiano de donde resulta la cristalización de la imagen personal de una vida realizada. De la phrónesis retenemos que tiene como horizonte la "vida buena"; como mediación, la deliberación; como actor, el phrónimos, y como puntos de aplicación, las situaciones singulares. (Ricoeur, 2006, p. 320)

La ética no es otra cosa que sabiduría práctica anclada en la experiencia y en el carácter. La pregunta por la formación del carácter es la cuestión clave, que implica preguntarse: ¿qué tipo de virtudes debe promoverse en la formación de los jóvenes investigadores?, ¿quién quiero ser? o ¿qué tipo 
de persona y de investigador quiero ser? Pues las virtudes son modos de ser, resultados de las experiencias de la vida y de la reflexión ardua sobre ellas, de modo que terminan haciéndose parte de cada uno, definiéndolo como persona, como sujeto social, como profesional. Pero estas cuestiones claves han ido quedando olvidadas a medida que se insiste cada vez más en las preocupaciones extrínsecas por la definición de los principios de las organizaciones que, se supone, los individuos deben interiorizar y aplicar cuando las circunstancias así lo exijan.

El enfoque de las virtudes, en cambio, apela a la necesidad de que cada uno se pregunte qué modo de ser quiere forjarse y a que persevere en un esfuerzo hermenéutico de sí mismo. Esto cobra mayor importancia en los campos de las ciencias humanas y sociales en los que, extrañamente, se ha pensado con frecuencia que no existirían demandas éticas explícitas como las que aparecen en los campos del saber en los que se realizan experimentos con seres vivos, por ejemplo. Pero ocurre justo lo contrario, en especial, en las investigaciones de perspectiva cualitativa, la investigación en campo, pues esta "[...] es un paradigma basado en la interacción humana, más bien que uno que está por fuera de esta interacción, y los investigadores de campo son en sí mismos los instrumentos de medición" (Muecke, 2003, p. 390).

Los compromisos con la investigación y, en sentido estricto, con las comunidades y sujetos investigados, y también con la sociedad, se perciben con mayor fuerza si se adoptan perspectivas como las que hoy predominan en ciencias humanas y sociales, pero también en el ámbito de la medicina y de la enfermería, como lo pone de manifiesto la autora mencionada, que es una enfermera investigadora:

Debido a que la etnografía depende de la interacción entre el investigador y el informante, las relaciones entre el investigador y el investigado son estrechas y multifocales, y los papeles se vuelven mucho más vagos que en los modelos positivistas donde se desanima la interacción entre investigador y sujeto. De hecho, los mandatos de la investigación cualitativa misma — formar relaciones y acercarse lo bastante a los informantes para ver el mundo a través de su perspectiva - genera asuntos éticos, tales como los que surgen del conflicto o de los límites difusos entre los papeles del investigador, el amigo y el clínico. (Muecke, 2003, p. 390)

En contextos como los que acabamos de indicar, la cuestión de cómo debe responder cada investigador a los múltiples y complejos problemas éticos que la práctica investigativa pueda presentarle en el futuro no es algo que pueda enfrentarse simplemente reclamando el estudio o la creación de códigos, o la formulación o aplicación de los principios; se trata más bien de que cada investigador se empeñe en acostumbrarse a actuar de unas 
ciertas maneras éticas que lo preparen para dar respuestas, lo más ajustadas posibles, a cada caso; esto es, debe empeñarse en educar su discernimiento y sus sentimientos de modo que cuente con mejores condiciones para afrontar los casos difíciles. Pero es preciso anotar que, como bien ha enseñado Gadamer, aun si se cuenta con principios claros, la cuestión clave sigue siendo cómo aplicarlos, es decir, cómo interpretarlos en cada circunstancia apremiante y abigarrada. Más, todavía, que la cuestión de la interpretación o aplicación de los principios remite inevitablemente al problema de quién es ese que interpreta, en última instancia, de cuál es su modo de ser ético como investigador.

\section{Conclusión}

En última instancia, nuestra defensa del enfoque de las virtudes como indispensable para pensar la formación ética de los investigadores, se sustenta en el hecho de que esta, al basarse en la sabiduría práctica como un saber anclado en un horizonte existencial amplio para evaluar decisiones y acciones y al conceder primacía a la respuesta de los casos concretos desde ese horizonte, incluye de hecho a las otras dos perspectivas. Al consecuencialismo, en la media en que la sabiduría práctica incluye la consideración de las consecuencias de las acciones, pero también incluye al deontologismo en cuanto, en el esfuerzo por obrar bien, es capaz de postular y de seguir principios, pero también porque sabe jerarquizarlos e interpretar su aplicación a cada situación, por ello incluye — desde Aristóteles- una noción de justicia correctiva, aquella que confía en que, si lo determinante es ser justos u obrar bien, esto debe perseguirse como lo central — contra todo formalismo— aun si es preciso corregir o abandonar la norma consagrada para regular el aspecto de la realidad en disputa.

Pero se sustenta, sobre todo, en que esta perspectiva o enfoque de las virtudes apuesta por una concepción de la ética afirmativa, no se contenta con mantener una actitud de responsabilidad o de cuidado, no se conforma con actuar cautamente para aminorar riesgos de daño, va mucho más allá: considera que lo que define esencialmente a la ética, y esto es determinante para formar investigadores, es su esfuerzo por ayudar a la realización plena de los sujetos y las comunidades, en ello reside todo su compromiso. Así se conecta con la política, tal como fue pensada originalmente en la antigüedad. 


\section{Referencias}

Amaya, A. (2009). Virtudes judiciales y argumentación: una aproximación a la ética jurídica. México: Tribunal Electoral del Poder Judicial de la Federación.

Amaya, A. (2012). The Role of Virtue in Legal Justification. En A. Amaya y L. Ho (Eds.), Law, Virtue and Justice (pp. 51-66). Oxford: Hart Publishing.

Aristóteles. (2010). Ética nicomaquea. Madrid: Gredos.

Bourdieu, P. y Wacquant, L. (2005). Una invitación a la sociología reflexiva. Buenos Aires: Siglo xxı.

Brandt, R. (1994). Teoría ética. Madrid: Alianza.

Bugallo, A. (2011). La filosofía ambiental en Arne Naess: influencias de Spinoza y James. Buenos Aires: Icala.

Camps, V. (2011). El gobierno de las emociones. Madrid: Herder.

Cuadros, R. (2009). Humanismo griego. En R. Cuadros (Ed.), Perspectivas sobre el humanismo (pp. 17-36). Ibagué: Universidad de Ibagué.

Cuadros, R. (2015). Retórica, ética y phrónesis: consideraciones sobre la racionalidad práctica en Chaim Perelman. En Transformaciones del pensamiento ético: continuidades y rupturas (pp. 11-31). Bogotá: Corporación Universitaria Minuto de Dios (Uniminuto).

Cuadros, R. (2016). Sobre la enseñabilidad de la ética. En Ética y racionalidad práctica. Enfoques y aplicaciones (pp. 11-29). Bogotá: Uniminuto-Sociedad Colombiana de Filosofía.

Gadamer, H. (1991). Verdad y método: fundamentación de la hermenéutica filosófica. Salamanca: Sígueme.

Gadamer, H. (2001). El giro hermenéutico. Madrid: Cátedra.

Glover, J. (2001). Humanidad e inhumanidad: una historia moral del siglo xx. Madrid: Cátedra.

Habermas, J. (2000). Aclaraciones a la ética del discurso. Madrid: Trotta.

Korsgaard, C. (2000). Las fuentes de la normatividad. Ciudad de México: Instituto de Investigaciones Filosóficas.

MacIntyre, A. (2001). Tras la virtud A. Valcárcel (Trad.). Barcelona: Crítica.

Mill, J. S. (1984). El utilitarismo. Madrid: Alianza.

Muecke, M. (2003). Asuntos éticos en la etnografía. En J. M. Morse (ed.), Asuntos críticos en los métodos de investigación cualitativa (pp. 389390). Medellín: Universidad de Antioquia.

Rachels, J. (2006). Introducción a la filosofía Moral. Ciudad de México: Fondo de Cultura Económica. 
Ricoeur, P. (1996). Sí mismo como otro (trad. Agustín Neira Calvo). Ciudad de México: Siglo xxı.

Ricoeur, P. (2006). La vida: un relato en busca de narrador. Ágora: Papeles de Filosofía, 25(2), 9-22.

Wingspread Conference on the Precautionary Principle. (1998). The Science and Environmental Health Network.

Wood, A. (2007). Kantian Ethics. Cambridge: Cambridge University Press. 